\title{
Identification of Key Actors of Agricultural Community-based Organization from Communication Perspective in Malaysia
}

\author{
N. N. M. Shariff ${ }^{1, *}$, A. Muhammad ${ }^{2}$, Z. S. Hamidi ${ }^{3}$ \\ ${ }^{1}$ Academy of Contemporary Islamic Studies (ACIS), MARA University of Technology, \\ 40450, Shah Alam, Selangor, Malaysia \\ 2Perdana School of Science, Technology and Innovation Policy (UTM Perdana School), Level 6, \\ Razak Tower, Universiti Teknologi Malaysia Kuala Lumpur, Jalan Semarak, \\ 54100 Kuala Lumpur, Malaysia \\ ${ }^{3}$ School of Physics and Material Sciences, Faculty of Sciences, MARA University of Technology, \\ 40450, Shah Alam, Selangor, Malaysia \\ *E-mail address: nur.nafhatun.ms@gmail.com
}

\begin{abstract}
This paper was part of a larger study which focuses on communication aspect of sustainable agriculture. To date, most of communication issues highlight role of extension officer rather than CBOs or the farmers meaning from top to bottom approach. It is realized that the flows of communication and the exchanges between different actors are extremely significant especially to understand the current state of agriculture and to facilitate the learning process. This underscores the need for dialogues and interactions between different actors and networks. Hence, this research will focus on CBOs because of the changing focus from extension officers to CBOs also changes the agricultural perspective. The purpose of this paper is to identify key actors that involved in an agricultural community-based organization (CBO). By identifying key actors, we can understand: 1) characteristic of a $\mathrm{CBO}$; and 2) dissemination of agricultural knowledge - network. Therefore, a more sustainable agricultural practice can be embraced by many especially by conventional farmers.
\end{abstract}

Keywords: Sustainable agriculture; communication; community-based organization (CBO)

\section{INTRODUCTION}

In this study, we shall focus on one of human activity that affected us the most i.e. agriculture. From that point, we will look at communication or network aspect of agriculture. Agriculture sector can contribute to expedite sustainability because: 1) agricultural sectors use the most land thus can have very significant influence on the environment; and 2) the end product of agriculture has often been food, making it one of the foundations of human society. The agriculture sector is one of the government's priority areas due to its capacity to act as a tool for poverty eradication and improving societal welfare.

Communication is the key to enhancing the information flow along this food supply chain and ensuring that sustainable agriculture initiatives and products eventually reach potential 
consumers that may be thousands of miles away [1]. Therefore, orienting the public to the right choice is important. It is realized that the flows of communication and the exchanges between different actors are extremely significant especially to understand the current state of agriculture and to facilitate the learning process [2].

This underscores the need for dialogues and interactions between different actors and networks. Hence, knowledge/information must be in understandable form, so that it can be absorbed by the public and thus achieve the purpose. It must be understood that communication is not a mere addendum to the real business of sustainable development because it is probably the most significant part of it $[3,4]$. In Malaysia, sustainable agriculture usually initially promoted by other-than-government body be it NGOs, CBOs or individual persons [5-10]. The weaknesses of the current practice is underlined by the fact that the knowledge/information is not well distributed, the unsustainable nature of the 'top-down' and 'supply-driven' approach, the lack of clarity of roles and responsibility of government agencies and the little emphasis on expenditure in agriculture.

This research will focus on the roles of CBOs because changing the focus from extension officers to CBOs also changes the agricultural perspective. There are several reasons why CBOs are the suitable actors to play the role of communicators which are: 1) agriculture itself is regarded as community work; 2) a community is small enough to be realistically and reachable because an individual alone is too small and powerless while the government and other big company/organization too out of touch; and 3) small farms tend to use their land less intensively compared to large farms - a practice that is potentially is less environmentally damaging and could foster long-term agricultural growth.

\section{STUDY SITE}

This study is based on long-term field studies during 2010-2012. It was conducted in Sekinchan, Selangor, Malaysia. Sekinchan stretches out at latitude $3^{\circ} 42^{\prime}$ North and $101^{\circ} 3^{\prime}$ East. Sekinchan is about $100 \mathrm{~km}$ from Kuala Lumpur and is situated along the main coastal main road between Tanjong Karang to the south and Sungai Besar to the north. The majority population of Sabak Bernam is Malay that is representing $74.1 \%$, followed by Chinese 19.35 $\%$, Indian $3.84 \%$ and others $2.71 \%$ [11]. Selangor is considered as the sixth state of Malaysia that provides agricultural product to consumers [12]. The land area as much as 433.83 square $\mathrm{km}(43.54 \%)$ is allocated for agriculture purpose which is the second highest after forest reserves (44.49\%). Other land usage are roads $(6.62 \%)$, residential area $(2.39 \%)$, government's land $(1.67 \%)$, institutional and public facilities $(0.49 \%)$, recreation area $(0.61$ $\%)$ and business and industrial area $(0.19 \%)$ [11].

Rice farming has been monopolizing the use of land with a total of $93.5 \%$ making it the most important agricultural activities. Paddy land of Sekinchan is part of Tanjong Karang Irrigation Scheme (TKIS). The paddy land is divided into 16 paddy blocks. Each of it is divided into paddy lots of about 3 acres (1.2 ha) [13]. Other agricultural land usages include vegetables/cash crop (4.7\%), orchard $(1.2 \%)$ and palm oil $(0.5 \%)$. 


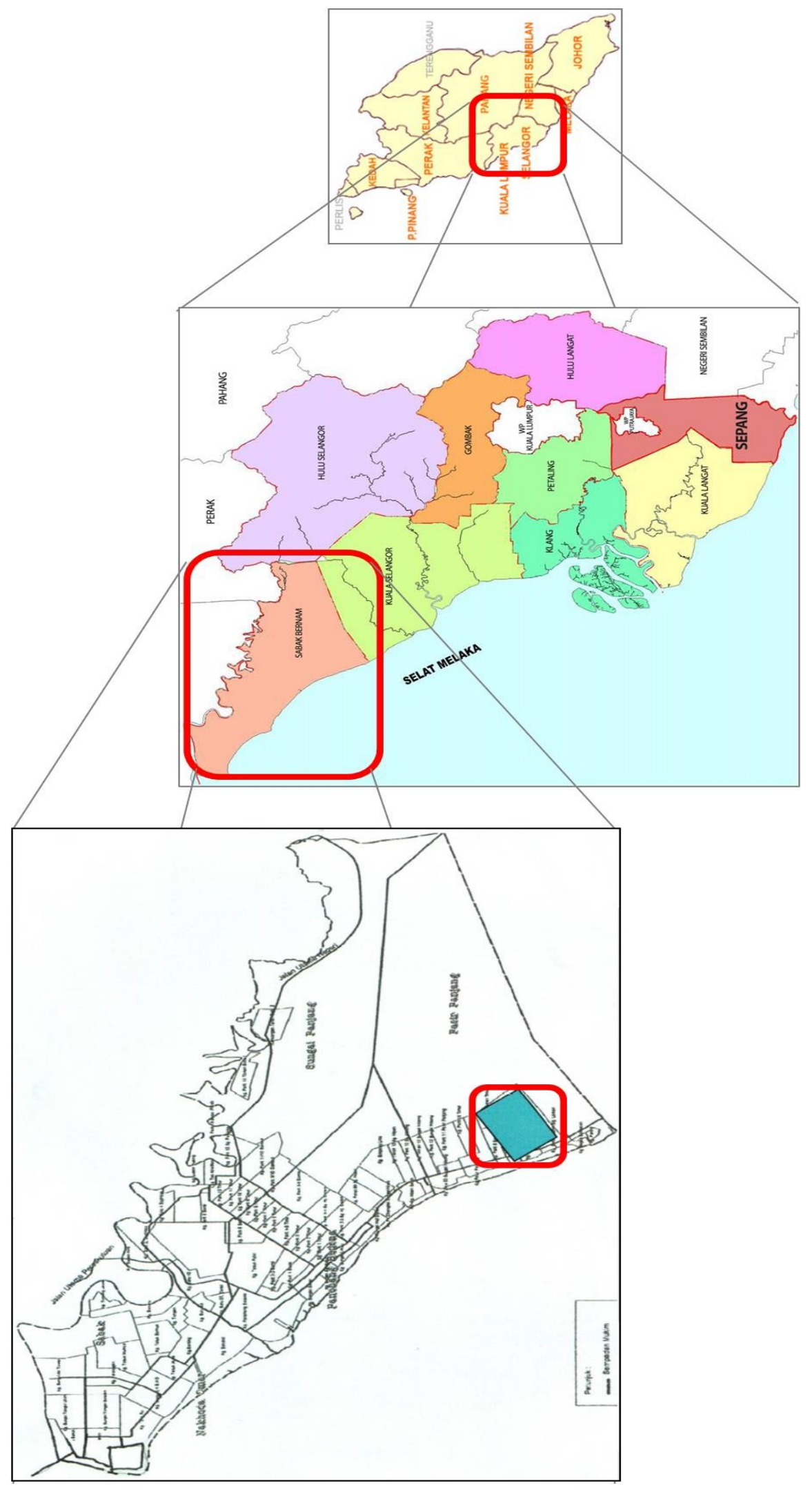

Figure 1. Map of Sekinchan, Selangor. 


\section{COMMUNITY-BASED ORGANIZATION}

The SRI D'9 name is taken from acronym SRI (System of Rice Intensification) as their main agricultural product and D'9 taken from their exact location i.e. Parit 9 (lit. ditch). The SRI D'9 consists of individual farmers who have their own land. This SRI D'9 is under the tutelage of Selangor DOA and it is not an ad hoc committee. It is a Malay Muslim communitybased organization located in Sungai Leman, Sekinchan, Selangor, Malaysia. As much as 148.8 ha of land are covered by the SRI D'9 (124 lots).

The farmers have been involved in agriculture for as long as 20 to 30 years. However, they still require updates in knowledge and information regarding agriculture. The efforts to convert to natural farming have started in September 2010 with Sungai Leman as its testing ground. After some positive results, the SRI D'9 was then founded in early 2011 [14].

\section{METHODOLOGY}

This exploratory study is best carried out using qualitative approach. In conducting the case studies and for better data analyses, triangulation technique was applied to analyze findings from different sets of data obtain through different methods $[15,17]$. The main techniques are: 1) 35 key informants for individual semi-structured interviews concurrent with field observations; and 2) data analysis e.g. observational notes, documents, any communication channels and audiovisual materials were used to uncover barriers and benefits. Among the most important aspect is Rapid Appraisal of Agricultural Knowledge System (RAAKS) was used to guide interview sessions and help analyze the data. RAAKS case studies were conducted to identify best practices and lesson learned about research, extension, education and communication linkages. This method was endorsed and used by IISD and rigorously tested in six (6) countries in Central America [18-20]. The application of RAAKS in this research is not for intervention or participation in any decision making but to harness with its established methodology. RAAKS' tools have the liberty to adapt (extending or combining them) or develop new tools. RAAKS' materials are easily reachable online at no cost.

\section{RESULTS}

This basic configuration diagram was constructed as an overview of the SRI D'9's AKIS. This configuration synthesis the result of communication networks, guided interview (semistructured), septagrams and feedback from them. There are 23 different (and overlapping) actors of the SRI D'9's communication networks which can be divided into six groups i.e. research, extension \& training, consumers, marketing, input suppliers and visitor. Three of them overlap each other: 1) Menteri Besar Incorporated (MBI) is involved in research and extension $\&$ training boundary; 2) Department of Agriculture (DOA) is involved in extension \& training and consumers; and 3) retailer is involved in marketing and input suppliers. An obvious connection between boundaries is consumers and marketing. Almost all actors have direct network with SRI D'9 except for International Rice Research Institute (IRRI), National University of Malaysia (UKM), Cornell University (CU), Felcra Training Centre (FTC), Bernas, DOA, and annual agriculture events whereby MBI and AE (extension officer) play a significant role in connecting the nodes. 

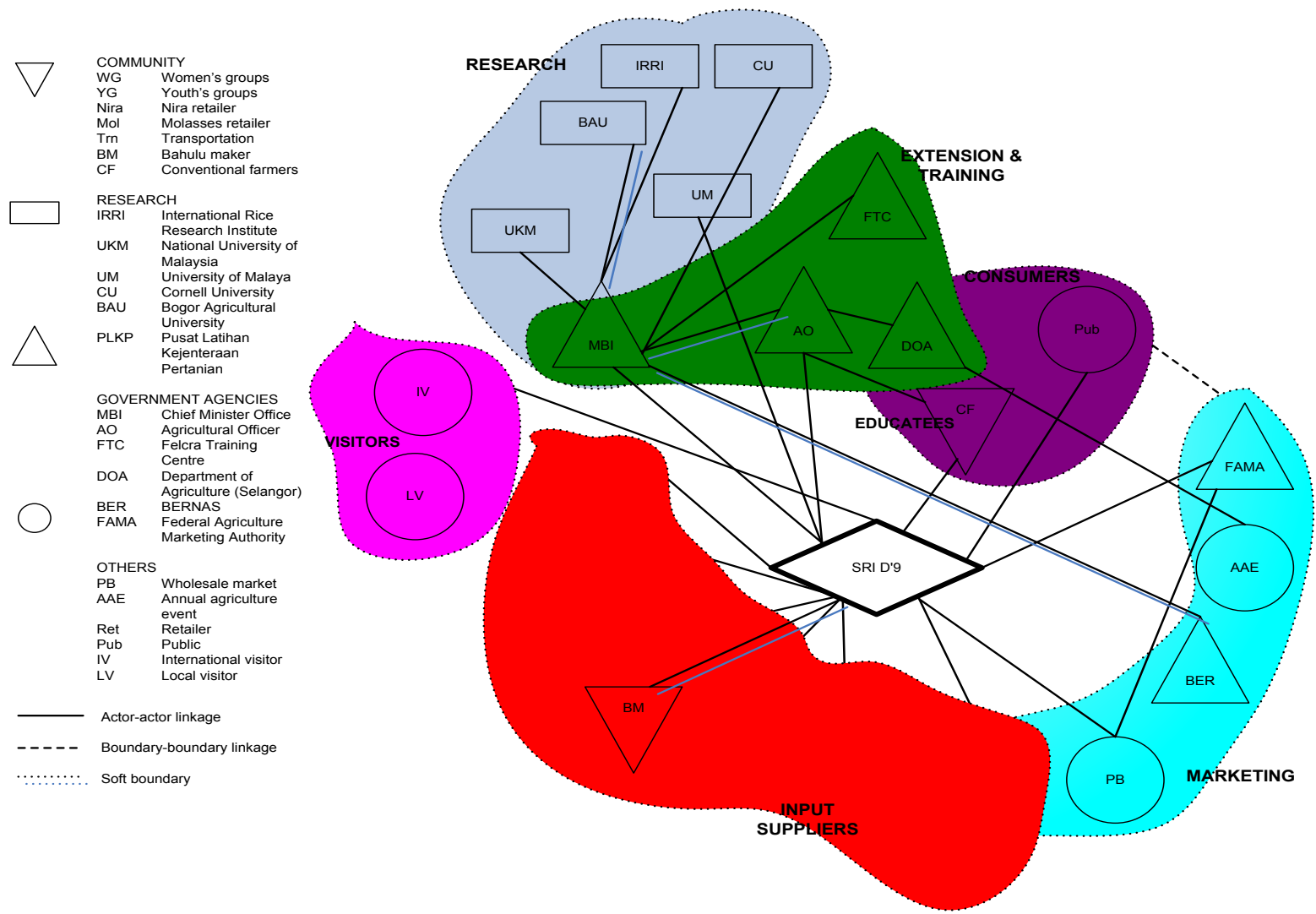

Figure 2. Basic Configuration.

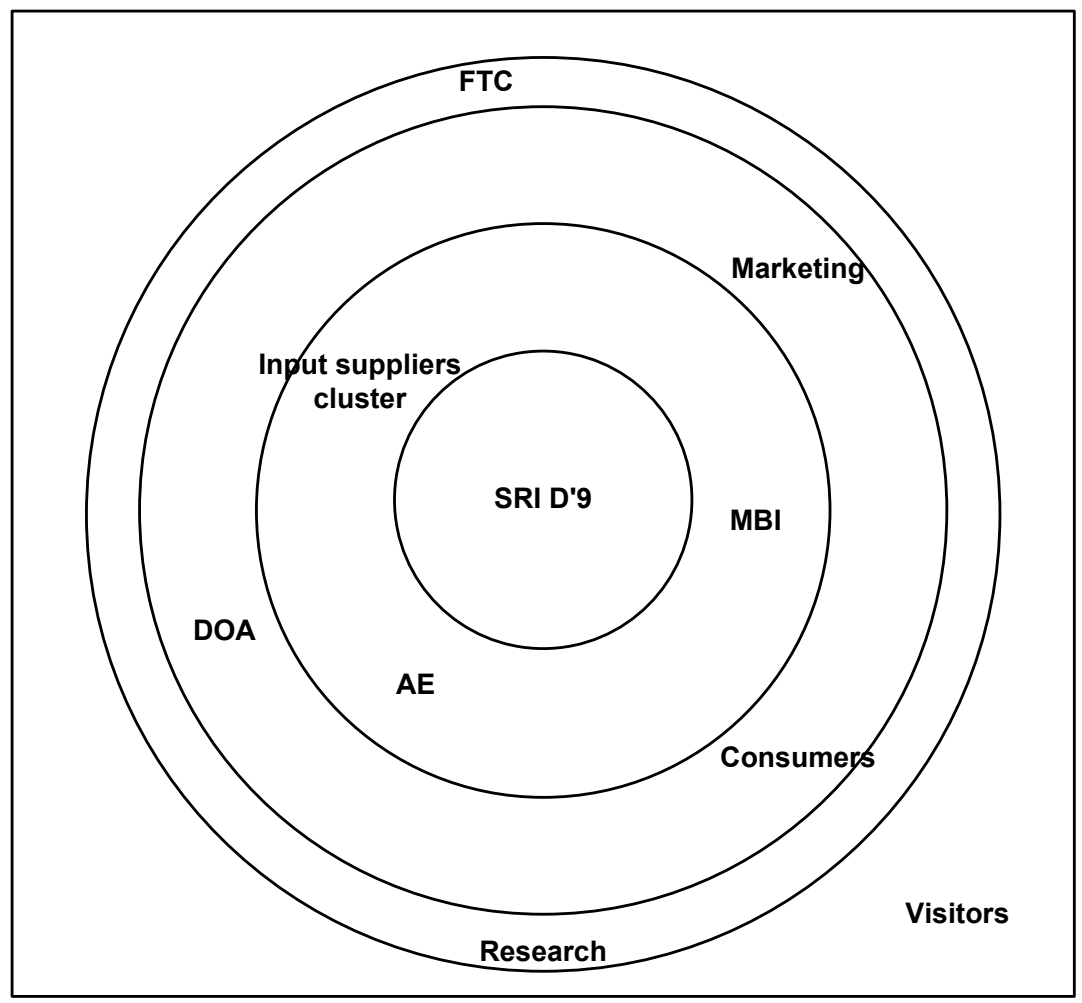

Figure 3. Communication Network Diagram. 
This communication network diagram shows the relative importance of networks. The abbreviation is located in Figure 2 (Basic Configuration). The closer the concentric ring to centre (the SRI D'9) indicates increased importance of the networks and directly means a higher frequency of knowledge/information exchange. In the case of the SRI D'9, the more important networks involve input suppliers cluster, extension officer and MBI. It is then followed by marketing cluster, consumers and DOA. Another outer ring is research cluster and FTC as a training centre. The least important actor is visitors.

\section{CONCLUSION}

This case study has identified some important findings on the SRI D'9. In the case of SRI D'9, we are able to identify the key actors that influenced SRI D'9 agricultural activities. It also shows that farmers (CBOs) can work hand in hand with government agencies to put into practice sustainable agriculture in Malaysia in their very own way. Suitable support should be given to them in the form of financial, R \& D facilities and moral.

\section{ACKNOWLEDGEMENT}

We thank supports by MARA Institute of Technology (UiTM) for the research grant and Ministry of Higher Education, University of Malaya for the Fellowship. We would like to thank Royal Tropical Institute (Koninklijk Instituut voor de Tropen; KIT) of The Netherland for providing KIT dossier free online access.

\section{BIOGRAPHY}

Dr Nur.Nafhatun.Md Shariff: She is a senior lecturer at Academy of Contemporary Islamic Studies, MARA University of Technology, Shah Alam, Malaysia. Her academic backgrounds are Islamic astronomy, sustainable agriculture and communication. She finds it interesting if she is able to do cross-field research.

Dr Amran Muhammad: He is a senior lecturer at Malaysia University of Technology (UTM). He is very active in NGO - KEMUDI. His areas of expertise are including policy and philosophy of science, technology and innovation, philosophy of sustainability and epistemology and sociology of knowledge.

Dr Zety Sharizat Hamidi: She is a senior lecturer at Faculty of Applied Sciences, MARA University of Technology, Shah Alam, Malaysia. She developed interest regarding sustainable agriculture after several time involved in agricultural activities. And later she finds out such agricultural lands are sometimes best candidates for radio lowinterference sites.

\section{References}

[1] C. Seek, R. Goldberg, M. Wendenbaum, The Role of Communication in Linking Sustainable Tourism Development, in: L. Grenna, R. Hilburner, E. Santi, G. Vereczi (Eds.), Communication and Sustainable Tourism, USAID, 2006.

[2] N. N. M. Shariff, Z. S. Hamidi, A. Muhammad, Dominant Media of a Community-Based Organization for Disseminating Sustainable Agriculture Knowledge and Information, International Journal of Agriculture and Forestry 3 (2013) 60-65.

[3] L. Shea, S. Montillaud-Joyel, Communicating Sustainbility: How to Produce Effective Public Campaign, United Nations Environment Programme, London, 2005. 
[4] W. Leal, Communicating Sustainability, Communicating Sustainable Development: A Practical Guide for Communications and Media Professionals, World Business Council for Sustainable Development, Hamburg, 2007.

[5] F. Ahmad, Sustainable Agriculture System in Malaysia, Regional Workshop on Integrated Plant Nutrition System (IPNS), United Nations Bangkok, 2001.

[6] E.C. Daño, E.D. Samonte, Public Sector Intervention in the Rice Industry in Malaysia, Southeast Asia Regional Initiatives for Community Empowerment (SEARICE), Bohol, 2010 .

[7] FAO, Malaysia: Country Profiles for Organic Agriculture, FAO, Rome, 2005.

[8] FAO, Awareness of organic agriculture, Malaysia: Country Profiles for Organic Agriculture, FAO, Rome, 2005.

[9] L. L. Tan, Global Compact Local Network - Malaysia, UN ESCAP, Kuala Lumpur, 2010.

[10] D. Wong, Peasants in the making: Malaysia's Green Revolution Institute of Southeast Asian Studies, Singapore, 1987.

[11] MDSB, Laporan 2010, MDSB, Sabak Bernam, 2010.

[12] MOA, Laporan Pertanian 2010, MOA, Kuala Lumpur 2010.

[13] N. N. M. Shariff, Z. S. Hamidi, A. Muhammad, Evidence for Generating High Margin Profit by Cost Cutting of Sustainable Agriculture Farming Input, American-Eurasian Journal Agricultural \& Environmental Science 13 (2013) 158-161.

[14] N. N. M. Shariff, The Role of Community-Based Organizations in Communicating Sustainability through Agriculture, Science and Technology Studies, University of Malaya, Kuala Lumpur, 2013.

[15] J. W. Creswell, Research Design: Qualitative, Quantitative and Mixed Methods Approaches, 2nd ed., Sage Publications, 2009.

[16] D. McKenzie-Mohr, Fostering Sustainable Behavior: Beyond Brochures, International Journal of Sustainability Communication 3 (2008) 108-118.

[17] N. Williams, How to Get a 2:1 in Media, Communication + Cultural Studies, SAGE Publications Ltd, London, 2004.

[18] P. G. H. Engel, M. L. Salomon, Facilitating innovation for development: A RAAKS resource box Royal Tropical Institute, Nederlands, 1997.

[19] P. G. H. Engel, The Social Organization of Innovation: A Focus on Stakeholder Interaction, Royal Tropical Institute, Wegeningen, 1997.

[20] A. Assefa, A. Waters-Bayer, R. Fincham, M. Mudahara, Comparison of frameworks for studying grassroots innovation: Agricultural Innovation Systems (AIS) and Agricultural Knowledge and Innovation Systems (AKIS), CGIAR, Addis Ababa, Ethiopia, 2009. 